\title{
SYNTHESIS AND CHARACTERIZATION OF ORGANIC/INORGANIC HYBRID MATERIALS BASED ON POLYHEDRAL OLIGOMERIC SILSESQUIOXANE (POSS) AND POLY(ETHYLENE GLYCOL) $V I A$ CLICK CHEMISTRY
}

\author{
Ghodsi MOHAMMADI ZIARANI, ${ }^{*}$ a Shima ASADI, ${ }^{\mathrm{a}}$ Alireza BADIEI ${ }^{\mathrm{b}}$ and Mohammad Reza NABID ${ }^{\mathrm{c}}$ \\ ${ }^{a}$ Department of Chemistry, Alzahra University, Vanak Square, Tehran, Iran \\ ${ }^{\mathrm{b}} \mathrm{Sch}$ ool of Chemistry, College of Science, University of Tehran, Tehran, Iran \\ ${ }^{c}$ Department of polymer, Faculty of Chemistry, Shahid Beheshti University, G.C, 1983969411, Tehran, Iran
}

$\mathrm{Cu}(\mathrm{I})$-catalyzed alkyne-azide Huisgen 1,3-dipolar cycloaddition (CuAAC) was used for the creation of POSS-PEG architecture. Herein, we presented the preparation of functionalized mono and bis $\mathrm{PEG}_{2000}$ with maleic anhydride. Then the mono and dialkyneterminated compounds were produced by the treatment with propargyl alcohol. Finally, click reaction occurred between azide end-functionalized polyhedral oligomeric silsesquioxane [POSS$\left.\left(\mathrm{N}_{3}\right)_{8}\right]$ and alkyne-terminated compounds. The resultant products were characterized by ${ }^{1} \mathrm{H}$ NMR, FT-IR, SEM, EDX, TGA and DTA.

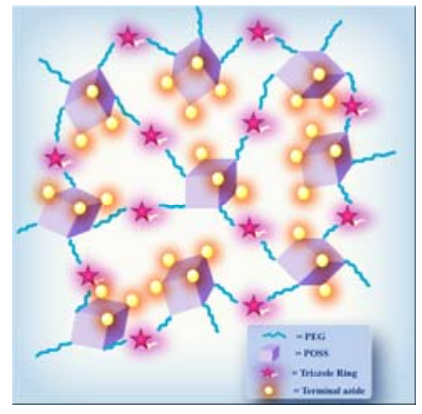

\section{INTRODUCTION}

Poly(ethylene glycol) (PEG), is a biocompatible polyether with prominent applications from industrial manufacturing to medicine which have been recently reviewed. ${ }^{1,2}$ This hydrophilic block has been used as PEG-functionalized polymers to produce amphiphilic systems. ${ }^{3}$

Polyhedral oligomeric silsesquioxane (POSS) is a class of unique inorganic nano-components with cubic inorganic core, and the composition of $\mathrm{R}_{8} \mathrm{Si}_{8} \mathrm{O}_{12}$ is the most studied form. This structure has some prominent properties such as welldefined, three dimensional and highly symmetric structure, low density, high temperature stability, the absence of trace metals, having size of about 1.5 $\mathrm{nm}$ in diameter, organic shell (eight $\mathrm{R}$ groups) surrounds the inorganic core. The POSS cage could demonstrate different compatibility in the polymer matrix by the modification of $\mathrm{R}$ groups. This organic layer can be varied from hydrogen to alkyl (methyl, isobutyl, cyclopentyl or cyclohexyl, etc.), alkylene, or arylene. According to these mechanical and thermal properties, POSS is a perfect building block for high performance polymer nanocomposites $^{4-6}$ and has been used in electronic devices, aerospace and biological applications.

However, inorganic-organic hybrid polymeric materials deserve to be expanded because of their combined properties of the organic and inorganic components. ${ }^{7-11}$ POSS molecules can be regarded as truly inorganic/organic hybrid system, which is compatible with polymers and natural biomaterials. $^{12}$

\footnotetext{
*Corresponding author. Tel.: +98-21-88041344; e-mail: gmziarani@hotmail.com; gmohammadi@alzahra.ac.ir
} 
There are several ways of preparing this kind of hybrid scaffold and "click chemistry" is one of the most commonly used which possesses excellent characteristics such as a short reaction time, high selectivity and mild reaction conditions. ${ }^{13}$

According to our previous efforts, ${ }^{14-19}$ we tried to investigate the synthesis of novel clickable structures, and characterization of hybrid polymer with POSS core. In this work the synthesis of an inorganic-organic hybrid polymer with POSS via click chemistry was investigated. In this hybrid polymer, poly(ethylene glycol) (PEG) was used as polymeric segment to be linked into POSS nano core and the click reaction was performed between azid POSS $\left[\mathrm{POSS}-\left(\mathrm{N}_{3}\right)_{8}\right]$ and alkynyl PEG.

\section{EXPERIMENTAL}

\section{Materials}

3-Chloropropyltrimethoxysilane, di- $n$-buthyltin dilaurate, sodium azide $\left(\mathrm{NaN}_{3}\right), \mathrm{CuSO}_{4}$, sodium acsorbate, maleic anhydride and concentrated $\mathrm{HCl}$ were obtained from Merck Co. Germany. $\mathrm{PEG}_{2000}$ with mono and bis $-\mathrm{OH}$ tails were purchased from Aldrich. In addition, 4-(dimethylamino) pyridine (DMAP), Propargyl alcohol and dicyclohexylcarbodiimide (DCC) were provided from Aldrich and used as received. Organic solvents, such as $N, N^{\prime}$-dimethylformamide (DMF), methanol and dichloromethane were of chemically pure grade, obtained from commercial sources. Before use, all solvents were purified by fractional distillation and dried.

\section{Instrumentation}

${ }^{1} \mathrm{H}$ NMR spectra were recorded on a BRUKER DRX-300 AVANCE spectrometer at $300.13 \mathrm{MHz}$ using $\mathrm{CDCl}_{3}$ or DMSO- $d_{6}$ as solvents. Infrared spectra were recorded in the wavenumbers ranging from 4000 to $400 \mathrm{~cm}^{-1}$ with a FT-IR Bruker Tensor 27 instrument using a $\mathrm{KBr}$ wafer. Melting points were measured using the capillary tube method with an electro thermal 9200 apparatus. Scanning electron microscopic (SEM) and images, energy-dispersive X-ray (EDX) analysis instruments were used to get electronic images of nanocomposites. The morphology of the nanocomposite was investigated by a Philips XL30 scanning electron microscope. Thermal behavior of the synthesized nanocomposites was studied by Thermogravimetric analysis (TGA) and Differential thermal analysis (DTA). TGA and DTA were conducted with a BAHR: STA 503 TGA/DTA instrument at a heating rate of $10^{\circ} \mathrm{C} \mathrm{min}^{-1}$ in air.

\section{Synthesis of POSS-(Cl) 8}

POSS- $(\mathrm{Cl})_{8}$ was prepared as followed: ${ }^{20} 3$-chloropropyltrimethoxysilane $(15 \mathrm{~g})$ was added to a mixture of concentrated $\mathrm{HCl}(5 \mathrm{~mL})$ and dry methanol $(150 \mathrm{~mL})$ in a two-necked roundbottom flask by a dropping funnel strongly stirring in $10 \mathrm{~min}$. After $2 \mathrm{~h}$, the mixture was cooled to the room temperature and remained statically for $48 \mathrm{~h}$. Di- $n$-buthyltin dilaurate $(0.15 \mathrm{~g})$ was added as catalyst. The white precipitated crystals were collected, washed with methanol for several times and dried in vacuum.

\section{Synthesis of POSS- $\left(\mathrm{N}_{3}\right)_{8}$}

Azidation of POSS- $(\mathrm{Cl})_{8}$ was carried out according to a typical procedure: ${ }^{9,21} \mathrm{NaN}_{3}(2.5 \mathrm{~g})$ was added to POSS- $(\mathrm{Cl})_{8}$ $(1 \mathrm{~g})$ and dry DMF $(30 \mathrm{~mL})$. After stirring at $393 \mathrm{~K}$ for $48 \mathrm{~h}$, the mixture was filtered. $100 \mathrm{ml}$ distilled water was added to the filtrate and extracted with $\mathrm{CH}_{2} \mathrm{Cl}_{2}(4 \times 20 \mathrm{~mL})$. The purified product was obtained after removal of the solvent and a yellow viscous liquid was obtained.

\section{Synthesis of M-PEG (3)}

A typical esterification procedure for the divergent reaction of two kinds of $\mathrm{PEG}_{2000}(\mathbf{2}$ and $\mathbf{4})$ with the maleic anhydride (1) is as follows: ${ }^{22}$ PEG (2) (3.0 g) was dissolved in $15 \mathrm{~mL}$ dry $\mathrm{CH}_{2} \mathrm{Cl}_{2}$, and maleic anhydride $(0.11 \mathrm{~g}, 1.5 \mathrm{mmol})$ and DMAP $(0.08 \mathrm{~g}, 1 \mathrm{mmol})$ were added subsequently. Then, the reaction vessel was cooled to $0{ }^{\circ} \mathrm{C}$ and diluted solution of the DCC $(0.2 \mathrm{~g}, 1 \mathrm{mmol})$ was added dropwise over $1 \mathrm{~h}$. The reaction was carried out at room temperature for $24 \mathrm{~h}$. The formed by-product, urea, was filtered off and the solvent removed. The resulting product was obtained by precipitation into excess methanol. The precipitation cycle was repeated twice and the brownish solid product (3) dried under vacuum at room temperature.

\section{Synthesis of M-PEG-M (5)}

Similar to above procedure, PEG (4) (3.0 g) was dissolved in $15 \mathrm{~mL}$ dry $\mathrm{CH}_{2} \mathrm{Cl}_{2}$, and maleic anhydride $(0.22 \mathrm{~g}, 3 \mathrm{mmol})$ and DMAP (0.16 g, $2 \mathrm{mmol})$ were added subsequently. Then, the reaction vessel was cooled to $0{ }^{\circ} \mathrm{C}$ and diluted solution of the DCC ( $0.4 \mathrm{~g}, 2 \mathrm{mmol})$ was added dropwise over $1 \mathrm{~h}$. The reaction was carried out at room temperature for $24 \mathrm{~h}$. The formed by-product, urea, was filtered off and the solvent removed. The resulting product was obtained by precipitation into excess methanol. The precipitation cycle was repeated twice and the brownish solid product (5) dried under vacuum at room temperature.

\section{Synthesis of alkyne-terminated M-PEG (7)}

Another esterification reaction was performed as followed: propargyl alcohol (6) $(0.5 \mathrm{~mL}, 10 \mathrm{mmol})$, DMAP (0.3 g, $3.75 \mathrm{mmol})$, and compound 3 (1.07 g, $0.5 \mathrm{mmol})$ were dissolved in dry $\mathrm{CH}_{2} \mathrm{Cl}_{2}$. Then, the reaction vessel was cooled to $0{ }^{\circ} \mathrm{C}$ and diluted solution of the DCC $(0.15 \mathrm{~g}, 0.75 \mathrm{mmol})$ was added dropwise over $1 \mathrm{~h}$. The reaction was carried out at room temperature for $24 \mathrm{~h}$. The formed by-product, urea, was filtered off and the solvent removed. The product (7) was obtained by precipitation into excess methanol.

\section{Synthesis of dialkyne-terminated M-PEG-M (8)}

As mentioned above, in the case of compound $\mathbf{5}$, the same treatment was occurred including: propargyl alcohol (6) ( $1 \mathrm{~mL}, 20 \mathrm{mmol})$, DMAP $(0.6 \mathrm{~g}, 7.5 \mathrm{mmol})$, and compound 5 ( $1 \mathrm{~g}, 0.5 \mathrm{mmol}$ ) were dissolved in dry $\mathrm{CH}_{2} \mathrm{Cl}_{2}$. Then, the reaction vessel was cooled to $0{ }^{\circ} \mathrm{C}$ and diluted solution of the DCC $(0.3 \mathrm{~g}, 1.5 \mathrm{mmol})$ was added dropwise over $1 \mathrm{~h}$. The reaction was carried out at room temperature for $24 \mathrm{~h}$. The formed by-product, urea, was filtered off and the solvent removed and the desired product $(\mathbf{8})$ was achieved.

\section{Click reaction between POSS- $\left(\mathrm{N}_{3}\right)_{8}$} and alkyne-terminated compounds

A solution of alkyne-terminated M-PEG (7) (0.108 g, 0.05 $\mathrm{mmol})$ in water was added to strongly stirring POSS- $\left(\mathrm{N}_{3}\right)_{8}$ $(0.12 \mathrm{~g}, 0.11 \mathrm{mmol})$ in $\mathrm{CH}_{2} \mathrm{Cl}_{2}$. $\mathrm{CuSO}_{4}$ and sodium acsorbate 
$1 \mathrm{M}(1 \mathrm{ml})$ were added to the mixture. The brownish precipitation was formed immediately and the mixture was stirred for $24 \mathrm{~h}$ at room temperature. The solid was separated by centrifuge and washed with dichloromethane and water and the final product (12) was obtained. In the same procedure, alkyne-terminated M-PEG-M (8) $(0.1 \mathrm{~g}, 0.05 \mathrm{mmol})$ in water was added to strongly stirring POSS- $\left(\mathrm{N}_{3}\right)_{8}(0.24 \mathrm{~g}, 0.22 \mathrm{mmol})$ in $\mathrm{CH}_{2} \mathrm{Cl}_{2} . \mathrm{CuSO}_{4}$ and sodium acsorbate $1 \mathrm{M}(2 \mathrm{ml})$ were added to the mixture. After producing a brownish precipitation, the mixture was left to stir for $24 \mathrm{~h}$ at ambient temperature. The solid was separated by centrifuge and washed with dichloromethane and water and the final product (13) was obtained and all resultant materials were characterized.

\section{RESULTS AND DISCUSSION}

In this study, two organic/inorganic POSS-PEG nanocomposites were synthesized via "click" chemistry. The synthetic route for the amphiphilic POSSPEG is depicted in Scheme 1 and 2. The PEG $_{2000}$ derivatives as one of the most commonly used hydrophilic polymers were used as starting materials. First, functionalization of PEG with small organic compounds was performed (Scheme 1). For this purpose, PEG was reacted with maleic anhydride to produce carboxylic acid terminated compounds [M-PEG (3) and M-PEG-M (5)]. Simple esterification reaction using DCC and DMAP was applied. The FT-IR spectrum (Fig. 1a) of M-PEG (3) showed a characteristic band for the ester at $1734 \mathrm{~cm}^{-1}$ and two bands for carboxyl end group at $1730 \mathrm{~cm}^{-1}$ and $2921 \mathrm{~cm}^{-1}$. ${ }^{1} \mathrm{H}$ NMR revealed the characteristic proton signals of the methylene protons of ethylene glycol $\left(-\mathrm{CH}_{2} \mathrm{CH}_{2}-\right)$ at 3.42-3.89 ppm and $-\mathrm{CH}=\mathrm{CH}-$ at 6.91. The same procedure was performed for the PEG with two $\mathrm{OH}$ tails (4) and subsequently M-PEG-M (5) was obtained in the first step. The FT-IR of compound $\mathbf{5}$ (Fig. 1b) had a sharp peak at $2920 \mathrm{~cm}^{-1}$ which is ascribed to the stretching vibration of carboxylic groups. Monoalkyne-terminated PEG (7) was prepared by the reactions of propargyl alcohol (6) with M-PEG (3). Dialkyne-terminated PEG (8) was produced by similar treatment as mentioned above. The Ft-IR spectra of compounds 7 and 8 are illustrated in Fig. 1c and 1d respectively. In these spectra a sharp peak at $2120 \mathrm{~cm}^{-1}$ which is attributed to the terminal alkynes is observed.

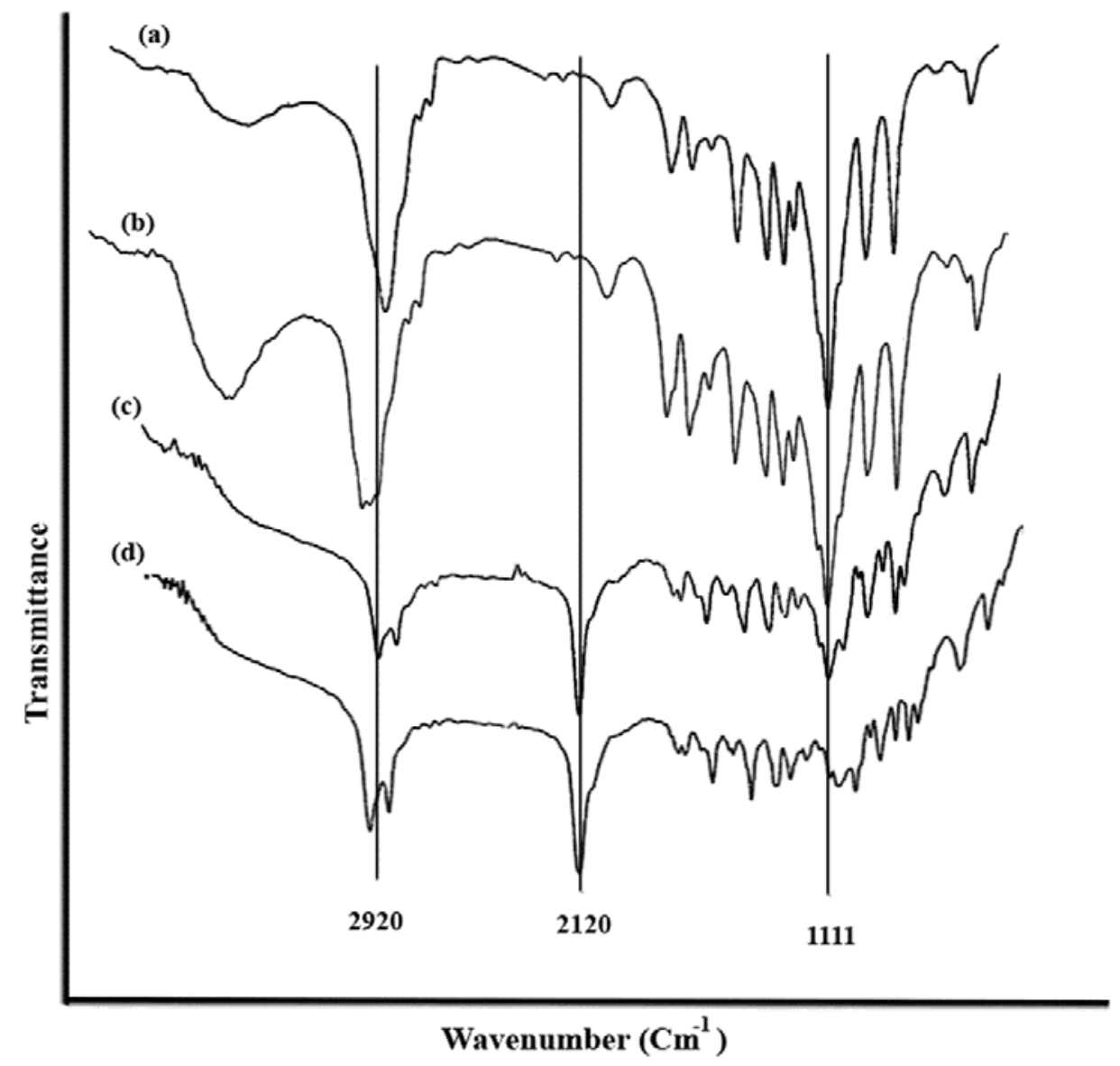

Fig. 1 - FT-IR spectra of (a) compound 3 (b) compound 5 (c) compound 7 and (d) compound 8. (The measurements were performed using dry $\mathrm{KBr}$ pellets). 

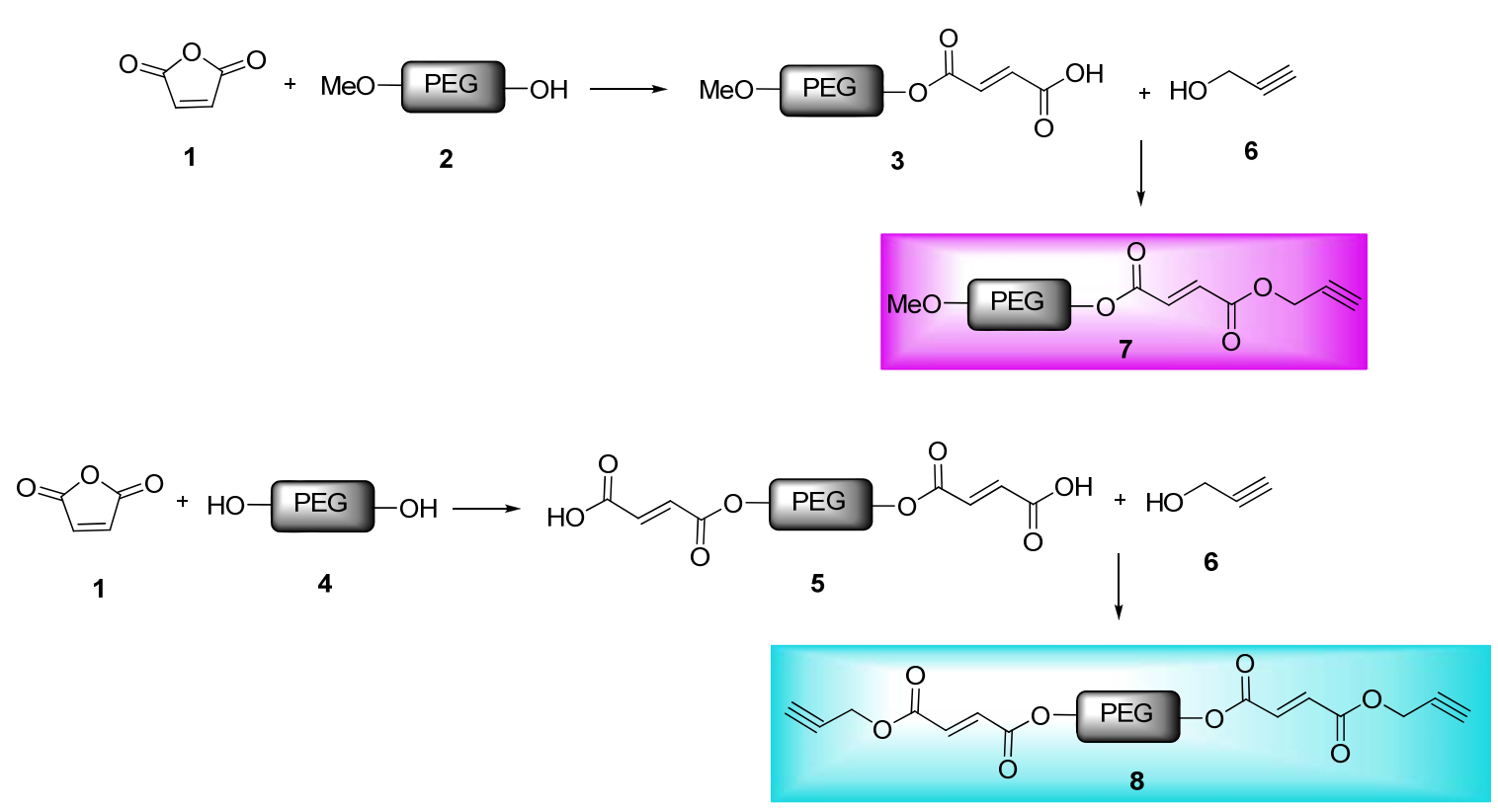

Scheme 1 - Preparation of compounds 7 and 8 by esterification reaction.

POSS- $(\mathrm{Cl})_{8}$ was prepared from 3chloropropyltrimethoxysilane as precursor. The terminal $\mathrm{Cl}$ functionality of POSS- $(\mathrm{Cl})_{8}$ was then easily converted to azide by reacting with $\mathrm{NaN}_{3}$ at $70{ }^{\circ} \mathrm{C}$.

The FT-IR spectrum of POSS- $(\mathrm{Cl})_{8}$ is shown in Fig. 2a. In this spectrum the peak at $740 \mathrm{~cm}^{-1}$ could be attributed to the $\mathrm{O}-\mathrm{H}$ out-of-plane vibration. The band due to the asymmetric $\mathrm{Si}-\mathrm{O}-\mathrm{Si}$ stretching vibration appears in $1100-1000 \mathrm{~cm}^{-1}$. The ${ }^{1} \mathrm{H}$ NMR of this compound clearly showed peaks of $\mathrm{CH}_{2}$ groups at $0.81,1.88$ and 3.54 (Fig. 3a). After azidation of POSS- $(\mathrm{Cl})_{8}$ by $\mathrm{NaN}_{3}$, it can be seen that the resonance signal of proton in $-\mathrm{CH}_{2} \mathrm{Cl}$ shifted from $3.5 \mathrm{ppm}$ to $3.2 \mathrm{ppm}$, the latter was ascribed to $-\mathrm{CH}_{2} \mathrm{~N}_{3}$ of POSS- $\left(\mathrm{N}_{3}\right)_{8}$ (Fig. 3b). This shielding demonstrates that the $-\mathrm{Cl}$ group has been replaced by an electron back drawing group which decreases the density of electrons around the protons and resulted to resonance in weaker field. This suggests that the azidation reaction was completed. The FT-IR of POSS- $\left(\mathrm{N}_{3}\right)_{8}$ (Fig. 2b) revealed the presence of absorbance peak at 2100 $\mathrm{cm}^{-1}$, which is characteristic of the terminal azide group.

In the last step, the above mono and dialkyneterminated PEG were reacted with POSS- $\left(\mathrm{N}_{3}\right)_{8}$ to obtain organic/inorganic POSS-PEG via click reaction. The Huisgen 1,3-dipolar cycloaddition was carried out at room temperature, with the mixture of $\mathrm{CuSO}_{4} /$ sodium ascorbate as the catalyst (Scheme 2).
The FT-IR of the resultant click products (13) (Fig. 2d) showed that the absorbance peak of azide group at 2100 is not suppressed. The same result was obtained for compound 12. It's assumed that the occurrence of click cyclization was not occurred for eight azide groups of POSS because of steric hindered of polymer segments and there were some remained azide tails. This phenomenon makes this hybrid to a clickable material which can be performed the click reaction with other smaller molecules. The protons resonance of triazole structures is observed at $7.97 \mathrm{ppm}$ therefore; the ${ }^{1} \mathrm{H}$ NMR spectrum indicated that organic/inorganic POSS-PEG was successfully obtained (Fig. 3c).

SEM experiments were carried out to monitor the structural evolution of these materials. Fig. 4a depicts the cubic structure of POSS- $(\mathrm{Cl})_{8}$ with a diameter of around $10 \mu \mathrm{m}$ which consists of numerous POSS- $(\mathrm{Cl})_{8}$ nanoparticles. The morphology of POSS after click reaction was illustrated in Fig. 4b.

The presence of some elements such as $\mathrm{Cl}, \mathrm{O}$ and $\mathrm{Si}$ in POSS- $(\mathrm{Cl})_{8}$ was confirmed by Energy Dispersive X-ray analysis (EDX) (Fig. 5a). EDX analysis of POSS- $\left(\mathrm{N}_{3}\right)_{8}$ in Fig. $5 \mathrm{~b}$ indicates that the clean product is mostly composed of $\mathrm{O}$ and $\mathrm{Si}$, with no other signals of $\mathrm{Cl}$ which shows the successful nucleophilic substitution.

The thermogravimetric analyses of the synthesized nanocomposites are displayed in Figure 6 . The shown curves represent the thermal decomposition of crude $\mathrm{PEG}_{2000}$, compounds $\mathbf{1 2}$ and $\mathbf{1 3 .}$ 


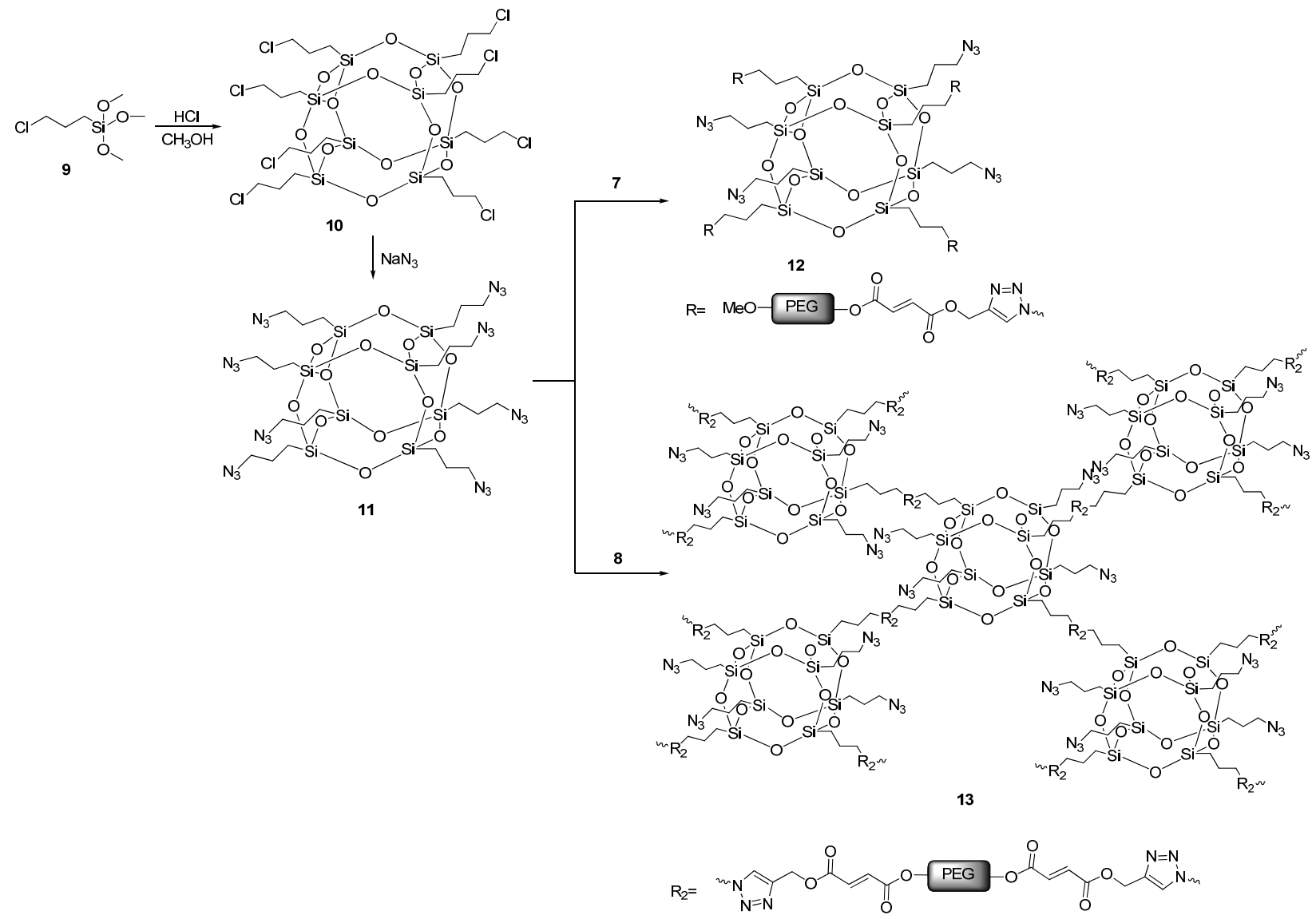

Scheme 2 - Synthesis of desired compounds 12 and 13 using click reaction between POSS- $\left(\mathrm{N}_{3}\right)_{8}$ and compounds 7 and 8 $\left(\mathrm{CDCl}_{3}\right.$ and TMS were used as the solvent and internal standard, respectively).

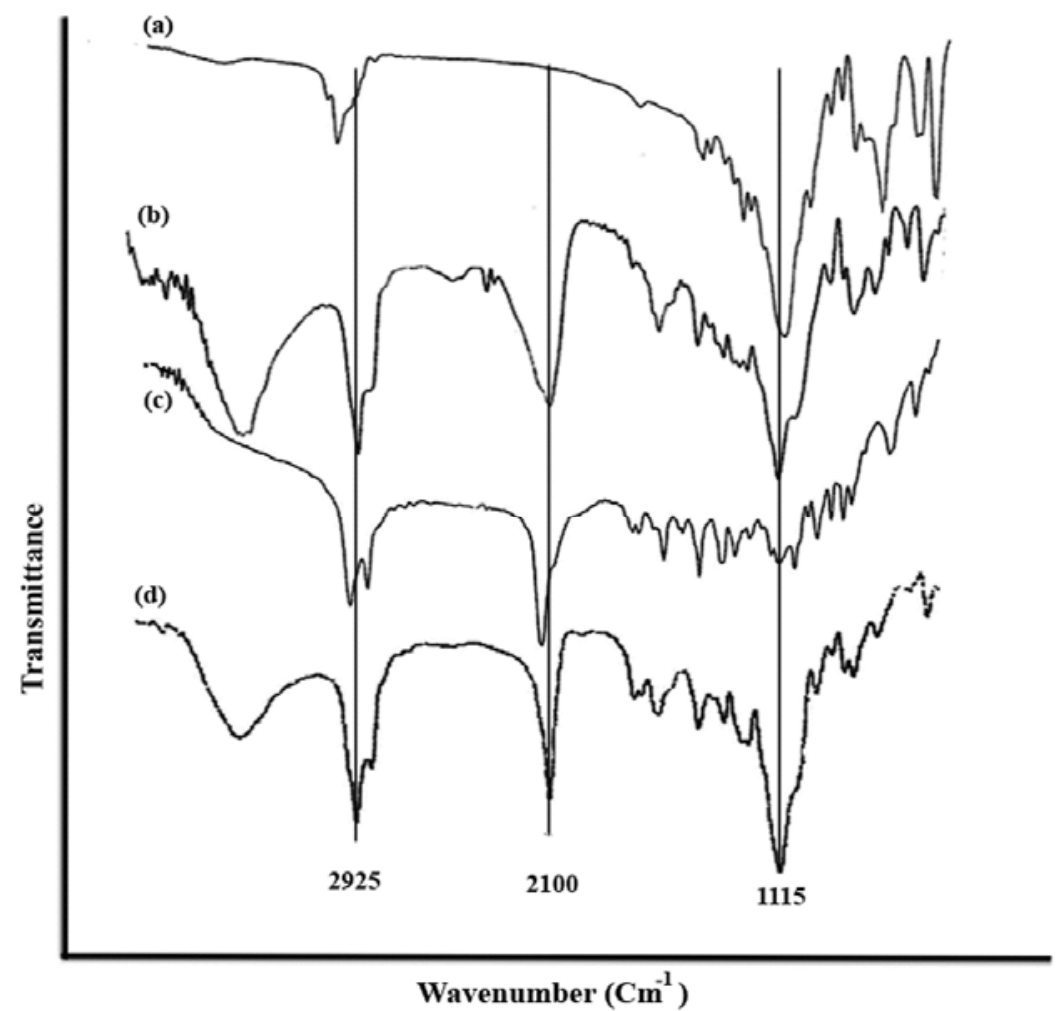

Fig. 2 - FT-IR spectra of (a) POSS- $(\mathrm{Cl})_{8}$ (b) POSS-(N $)_{8}$ (c) compound 8 and (d) compound 13. (The measurements were performed using dry $\mathrm{KBr}$ pellets). 
a)
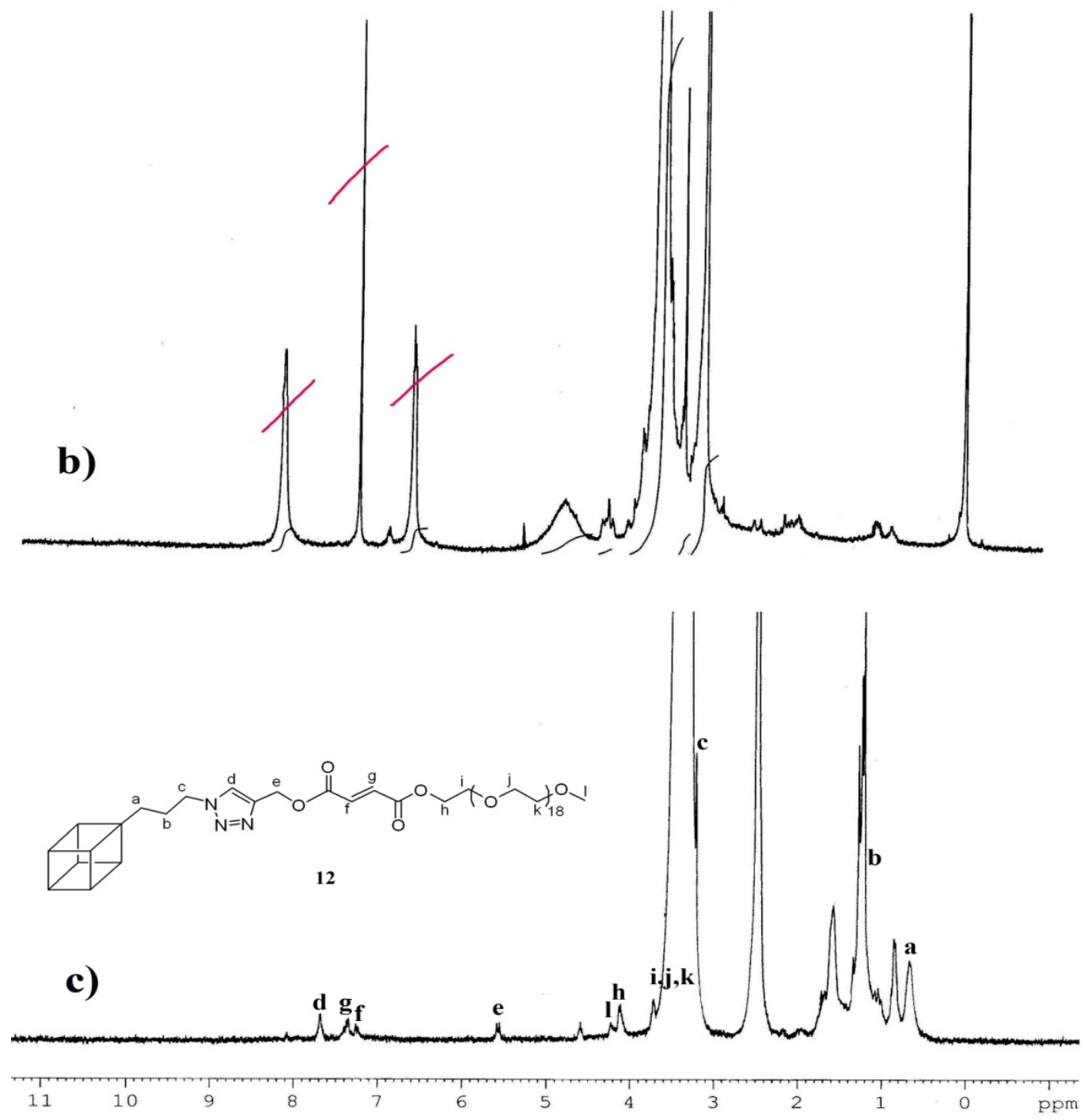

Fig. $3-{ }^{1} \mathrm{H}$ NMR spectra of (a) POSS- $(\mathrm{Cl})_{8}$ (b) POSS- $\left(\mathrm{N}_{3}\right)_{8}$ (c) compound 12 $\left(\mathrm{CDCl}_{3}\right.$ and TMS were used as the solvent and internal standard, respectively). 

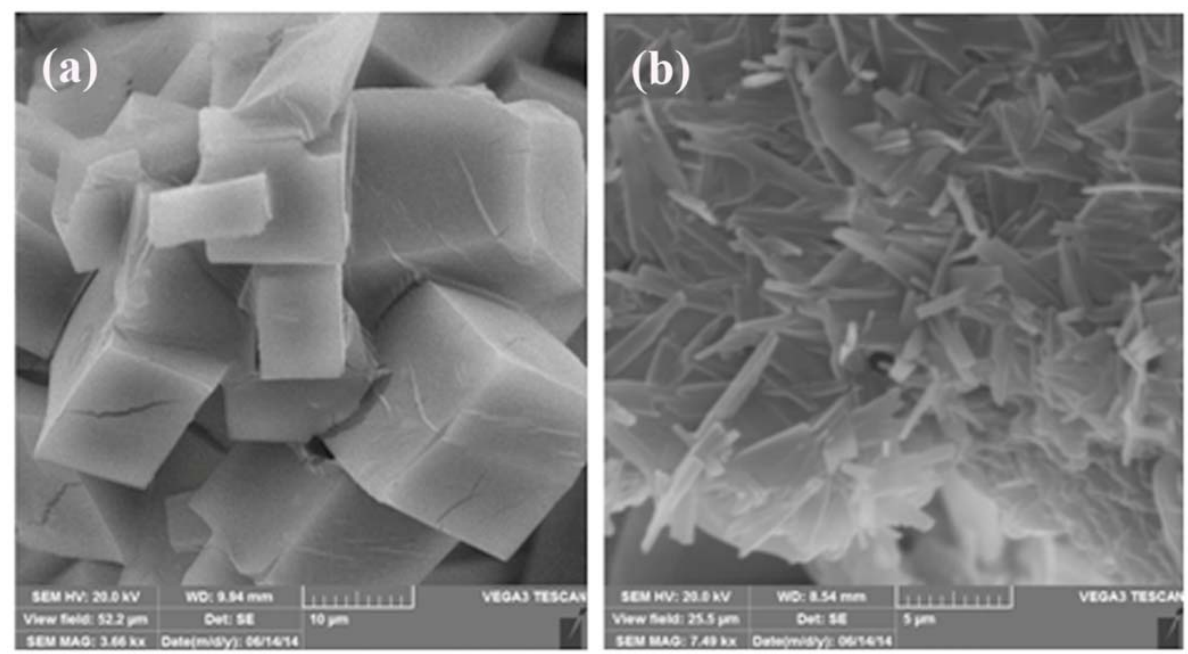

Fig. 4 - SEM of POSS- $(\mathrm{Cl})_{8}(\mathrm{a})$ and POSS- $\left(\mathrm{N}_{3}\right)_{8}$ (b).

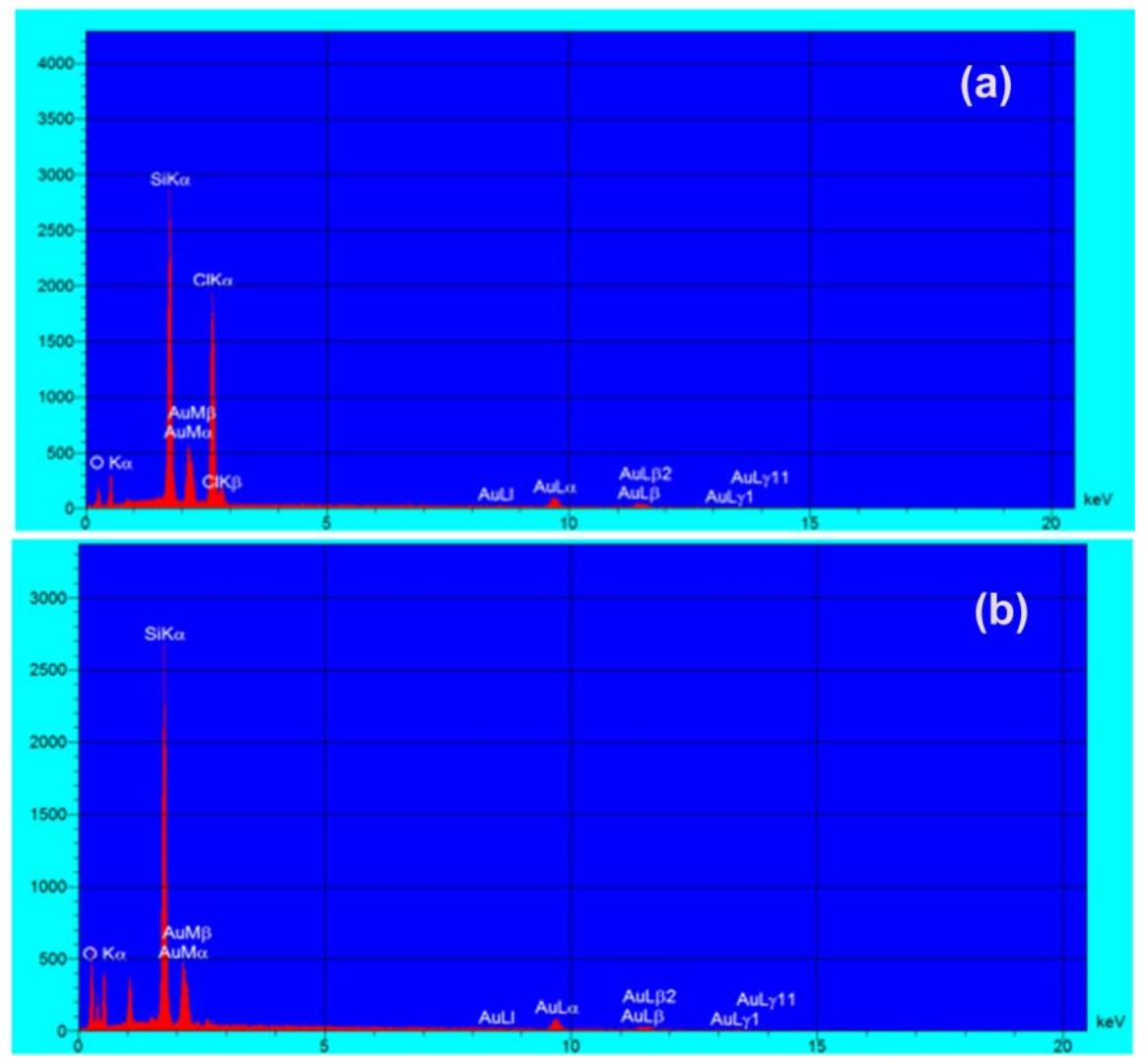

Fig. 5 - EDX analysis of (a) POSS- $(\mathrm{Cl})_{8}$ and (b) POSS-( $\left.\mathrm{N}_{3}\right)_{8}$.

In the case of $\mathrm{PEG}_{2000}$ a sharp weight loss was observed at $230{ }^{\circ} \mathrm{C}$, which was related to degradation of polymeric chain. At the end of analysis, nearly $100 \%$ of $\mathrm{PEG}_{2000}$ was consumed that revealed the complete degradation of the main skeleton. The curve of material $\mathbf{1 2}$ showed three steps of weight loss. The first loss observed from 185 to $250{ }^{\circ} \mathrm{C}$ was due to the degradation of polymeric segments. The second loss occurred from 270 to $400{ }^{\circ} \mathrm{C}$, attributed to the breaking of organic segments from the surface, and the third loss from 405 to $623{ }^{\circ} \mathrm{C}$ was maybe due to the thermal degradation of organic segments on the surface of POSS. The $15 \%$ of residue was related to burned silicon compounds. Similarly, in the case of compound 13, three weight loss in the ranges of 177-231, 270-384 and $400-658{ }^{\circ} \mathrm{C}$ were observed and $29 \%$ residue was left at the end of the experiment. 


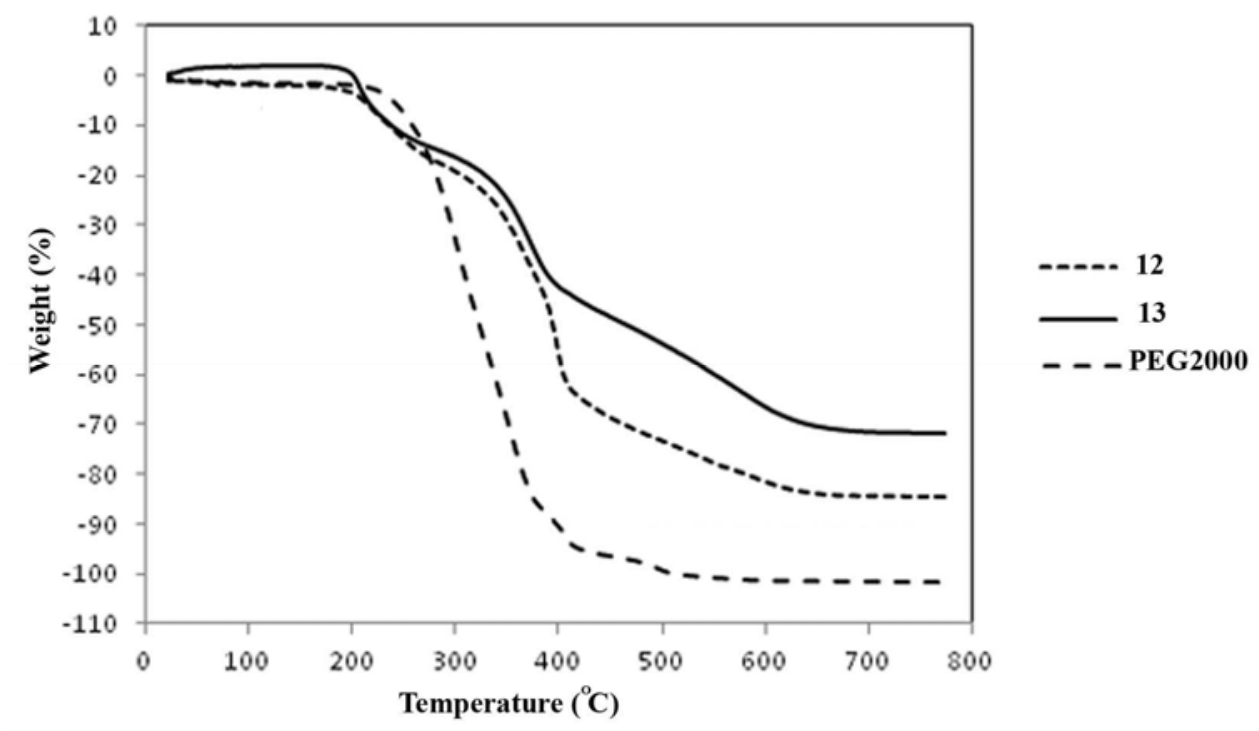

Fig. 6 - TGA analysis of crude $\mathrm{PEG}_{2000}$, compounds $\mathbf{1 2}$ and $\mathbf{1 3}$.

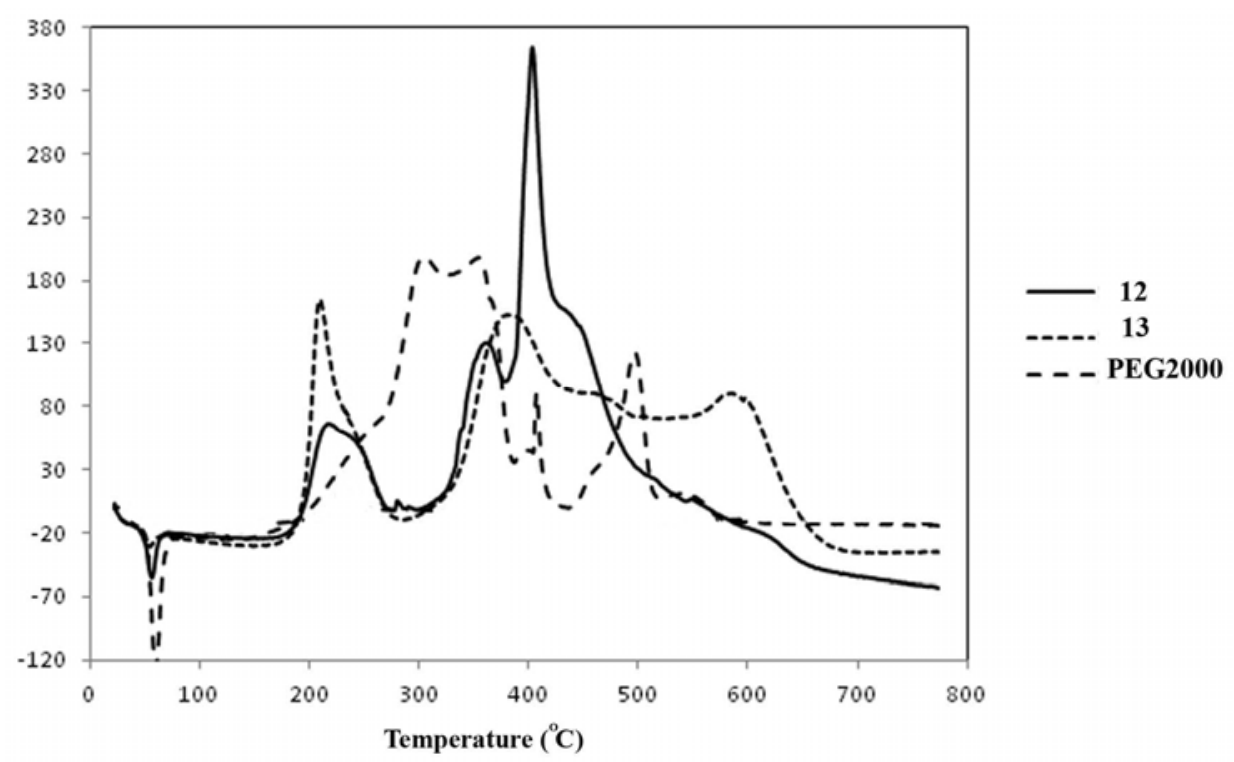

Fig. 7 - DTA analysis of crude $\mathrm{PEG}_{2000}$, compounds $\mathbf{1 2}$ and $\mathbf{1 3 .}$

The DTA analysis of crude $\mathrm{PEG}_{2000}$ and desired nanocomposites (compounds $\mathbf{1 2}$ and 13) was shown in Fig. 7. As can be seen, the $\mathrm{PEG}_{2000}$ spectral region was deconvoluted into two endo and exo region. The first peak in endo region at $55^{\circ} \mathrm{C}$ is related to loss of water. The main weight loss at 200-380 ${ }^{\circ} \mathrm{C}$ in TGA of $\mathrm{PEG}_{2000}$ was illustrated in DTA by a sharp peak in exo region. Another strong peak at $400-600{ }^{\circ} \mathrm{C}$ was attributed to aggregation of polymer chain. In DTA of compound $\mathbf{1 2}$ in addition to primary endo peak at $55{ }^{\circ} \mathrm{C}$ several exo peaks at $230,363,403$ and $434{ }^{\circ} \mathrm{C}$ were observed and were related to loss of organic moieties. The exo peaks of compound $\mathbf{1 3}$ appeared at the range of 206, 376, 463 and $583{ }^{\circ} \mathrm{C}$.

\section{CONCLUSION}

A novel polymeric organic-inorganic hybrid material based on POSS as nano core was successfully synthesized by click chemistry of POSS- $\left(\mathrm{N}_{3}\right)_{8}$ and alkynyl terminated PEG. First, we synthesized both mono- and bis maleic acid (M)functionalized poly(ethylene glycol) derivatives (M-PEG and M-PEG-M, respectively) through esterification reaction of maleic anhydride to $\mathrm{PEG}_{2000}$, using DCC and DMAP. Then, the following compounds were treated by propargyl alcohol via another similar esterification since the mono and dialkyne-terminated compounds were produced. In the second step, octakis(3- 
chloropropyl)octasilsesquioxane $\left[\mathrm{POSS}-(\mathrm{Cl})_{8}\right]$ as a nano cube-like $T_{8}$ silsesquioxanes was converted to azid POSS [POSS- $\left(\mathrm{N}_{3}\right)_{8}$ ] through nucleophilic substitution. Finally, azide end-functionalized polyhedral oligomeric silsesquioxane [POSS- $\left.\left(\mathrm{N}_{3}\right)_{8}\right]$ was incorporated into the mono- and bis PEGfunctionalized materials via highly efficient azidealkyne click reaction, resulting a hydrophilic/ hydrophobic system. The resultant organic/ inorganic hybrid materials were characterized by means of ${ }^{1} \mathrm{H}$ NMR, FT-IR, SEM, EDX, TGA and DTA.

Acknowledgements. We gratefully acknowledge the financial support from the Research Council of Alzahra University.

\section{REFERENCES}

1. T. R. Hoare and D. S. Kohane, Polymer, 2008, 49, 19932007.

2. J. K. Tessmar and A. M. Göpferich, Macromol. Biosci., 2007, 7, 23-39.

3. W. H. Binder and R. Sachsenhofer, Macromol. Rapid Commun., 2008, 29, 952-981.

4. B.-S. Kim and P. T. Mather, Macromol., 2002, 35, 83788384.

5. B.-S. Kim and P. T. Mather, Polymer, 2006, 47, 6202-6207.

6. B.-S. Kim and P. T. Mather, Macromol., 2006, 39, 9253 9260 .
7. C.-C. Liao, H.-Y. Wu, D.Saikia, Y.-C. Pan, Y.-K. Chen, G. T. K. Fey and H.-M. Kao, Macromol., 2008, 41, 8956-8959.

8. M. Y. Lo, C. Zhen, M. Lauters, G. E. Jabbour and A. Sellinger, J. Amer. Chem. Soc., 2007, 129, 5808-5809.

9. W. Yuan, X. Liu, H. Zou, J. Li, H. Yuan and J. Ren, Macromol. Chem. Phys., 2013, 214, 1580-1589.

10. S. Muthukrishnan, F. Plamper, H. Mori and A. H. E. Müller, Macromol., 2005, 38, 10631-10642.

11. X. Liu, Z. Tian, C. Chen and H. R. Allcock, Macromol., 2012, 45, 1417-1426.

12. J. Wu and P. T. Mather, Polymer Rev., 2009, 49, 25-63.

13. H. C. Kolb, M. G. Finn and K. B. Sharpless, Angew. Chem. Int. Ed., 2001, 40, 2004-2021.

14. G. Mohammadi Ziarani, M. Shakiba Nahad, N. Lashgari and A. Badiei, Acta Chim. Slov., 2015, 62, 1-7.

15. Y. Khaniani and A. Badiei, J. Mater. Res., 2012, 27, 932938.

16. G. Mohammadi Ziarani, N. Lashgari, P. Hajiabbas, A. Badiei; Int. J. Bioinorg. Hybrid Nanomater., 2018, 7, 5-12.

17. M. Rahimifard, G. Mohammadi Ziarani, A. Badiei, F. Yazdian, J. Inorg. Organometal. Polym. Mater., 2017, 27, 1037-1044

18. G. Mohammadi Ziarani, Z. Hassanzadeh, P. Gholamzadeh, S. Asadi, A. Badiei, RSC Adv., 2016, 6, 21979-22006.

19. M. Karimi, A. Badiei, G. Mohammadi Ziarani, Inorg. Chim. Acta, 2016, 450, 346-352.

20. M. J. Fernández-Merino, L. Guardia, J. I. Paredes, S. VillarRodil, A. Martínez-Alonso and J. M. Tascón, RSC Adv., 2013, 3, 18323-18331.

21. E. Gungor, C. Bilir, H. Durmaz, G. Hizal and U. Tunca, J. Polym. Sci. A: Polym. Chem., 2009, 47, 5947-5953.

22. L. Chen, B. Zeng, J. Xie, S. Yu, C. Yuan, Y. Pan, W. Luo, X. Liu, K. He and Y. Xu, Reac. Funct. Polym., 2013, 73, 1022-1029. 
